\title{
Is there still a role for spontaneous reporting of adverse drug reactions?
}

\section{Joel Lexchin}

I $\mathrm{n}$ an age of large, linked databases, is there still a role for a system of spontaneous reporting of adverse drug reactions? The problems associated with reports are wellknown: poor quality of submitted reports; significant underreporting of adverse reactions; difficulty in calculating rates because of incomplete numerator data along with unreliable denominators; and limited ability to establish cause and effect. ${ }^{1}$

In this commentary I discuss the importance of reporting adverse reactions and possible ways to increase the rate of reporting. How to analyze signals that are generated through reporting and what action to take on these signals are outside my scope, since these are issues that will exist in any type of postmarketing surveillance system.

Modern computer technology, which allows linking of multiple databases, could easily be used to record prescriptions filled for selected products and then follow people receiving these prescriptions through records of physician visits and hospital admissions, and through cancer and death registries. Integrated databases have been used for well over a decade in Saskatchewan to investigate safety issues around drugs. Their use in other provinces is more recent, but they were instrumental in discovering the increase in hospital admissions and death rates in Ontario associated with hyperkalemia and the use of spironolactone in treating congestive heart failure. ${ }^{2}$ Even with these capabilities, I believe that there is still a role for spontaneous reporting of adverse drug reactions.

Older evidence shows that formal postmarketing studies can miss adverse reactions detected by spontaneous reports. ${ }^{3}$ Computerized databases will work only for prescription drugs; adverse events involving over-the-counter medications will be missed. Even long-established over-the-counter products like phenylpropanolamine have been found to have side effects serious enough that they need to be pulled from the market. ${ }^{4}$ Interestingly, adverse reaction reports about this product started the chain of events that lead to its eventual withdrawal. ${ }^{5}$ Serious adverse effects from some drugs can take years to manifest; witness clear cell vaginal cancer among daughters of women who took diethylstilbestrol when pregnant. A system of spontaneous reporting may be more effective at picking up these remote problems.

There are more fundamental reasons to continue with a system of spontaneous reporting. Promoting the concept that adverse reactions should be reported emphasizes to everyone involved the importance of drug safety issues. Adverse reaction reporting also allows for a qualitative description of how the reactions affect patients' lives. One patient in the UK who took paroxetine reported that "the electric explosions in my head were triggered off by the movements from left to right of my eyes"; the adverse reaction record on file with regulators said "abnormal eye movements." This example illustrates how written reports of the same symptoms can differ. Imagine the difference between an adverse reaction picked up in a database and a written report of the same symptom.

If spontaneous reporting is worth preserving, it is clear that current practice needs significant improvement. British data suggest that underreporting may be as high as $98 \% .^{7}$ Even in the case of serious and unlabelled reactions, reports may only be filed for $\mathrm{I}$ in 4600 cases. ${ }^{8}$ Moore and associates noted that although the US Food and Drug Administration received an average of 82 reports annually about adverse reactions related to digoxin, in a 7-year period there were over 200000 admissions to hospital due to adverse reactions to that drug. ${ }^{9}$

In 2004, Health Canada received just over 10 ooo adverse reaction reports, with pharmacists as the primary source among those who identified themselves (Table I). Lately there have been calls for mandatory reporting by physicians. However, making reporting mandatory is unlikely to produce any meaningful change in the quantity or quality of reports. ${ }^{10}$ Almost half of Canadian doctors oppose mandatory reporting and view it as an extra burden on their already busy lives. ${ }^{11}$ How would it be possible to police such a system? Payment has been shown to increase reporting rates, ${ }^{12}$ but if doctors are to be paid, what about nurses, pharmacists and patients?

\section{Almost half of Canadian doctors oppose mandatory reporting and view it as a burden.}

Goldman summarizes a number of methods that have proven successful in stimulating adverse reaction reporting in the medical community. ${ }^{13}$ These include educating doctors on the need to report; familiarizing them with the reporting system in general and the forms and guidelines in particular; and providing them with follow-up about reports that they have filed.

In the UK newly marketed drugs are marked with an inverted black triangle, which indicates that doctors should report all adverse reactions associated with these products. These black triangles appear beside the drug name in the British $\mathrm{Na}$ tional Formulary and in promotional material. Black-triangle drugs are monitored closely for a minimum of 2 years, and the symbol is not removed until the safety of the drug is well- 
Table 1: Number and percentage of adverse reaction reports by source of report, 1999-2004

\begin{tabular}{|c|c|c|c|c|c|c|}
\hline Source & 1999 & 2000 & 2001 & 2002 & 2003 & 2004 \\
\hline Pharmacist & $2103(37.0)$ & 2420 (32.9) & $2097(28.4)$ & $2141(25.0)$ & $2369(25.7)$ & $3011(29.4)$ \\
\hline Physician & $1446(25.4)$ & $1876(25.5)$ & $1914(25.9)$ & $2093(24.4)$ & $2176(23.6)$ & $2667(26.2)$ \\
\hline $\begin{array}{l}\text { Health } \\
\text { professional* }\end{array}$ & 1051 (18.5) & 1157 (15.7) & 1378 (18.6) & $1780(20.8)$ & $1974(21.4)$ & 1499 (14.6) \\
\hline $\begin{array}{l}\text { Consumer or } \\
\text { patient }\end{array}$ & $516 \quad(9.1)$ & $1010(13.7)$ & 1102 (14.9) & 1581 (18.5) & $1628(17.7)$ & $1928(18.8)$ \\
\hline Nurse & $447 \quad(7.9)$ & $381 \quad(5.2)$ & $443 \quad(6.0)$ & $421 \quad(4.9)$ & 689 (7.5) & $873 \quad(8.5)$ \\
\hline Other & $125 \quad(2.2)$ & $517 \quad(7.0)$ & $455 \quad(6.2)$ & $550 \quad(6.4)$ & $373 \quad(4.1)$ & $260 \quad(2.5)$ \\
\hline Total & $5688(100)$ & 7361 (100) & 7389 (100) & 8566 (100) & 9209 (100) & $10238(100)$ \\
\hline $\begin{array}{l}\text { Change from } \\
\text { previous yr, \% }\end{array}$ & - & 29.4 & 0.4 & 15.9 & 7.5 & 11.2 \\
\hline
\end{tabular}

Source: Health Canada. Canadian Adverse Reaction Newsletter April 2001:2(2); April 2003:13(2); April 2005:15(2). Available: www.hc-sc.gc.ca/dhp-mps/medeff/bulletin/index_e.html

*Type not specified in report.

established. This system could be adapted for use in Canada, with a similar symbol appearing in the Compendium of Pharmaceuticals and Specialties and on all promotional material. In addition, it could be made mandatory for drug company sales representatives to inform doctors about drugs carrying this symbol that are made by their company.

To date, Health Canada has taken a few modest steps to improve reporting by establishing regional reporting centres, setting up a central Web site (www.hc-sc.gc.ca/dhp-mps/ medeff/report-declaration/index_e.html) and providing channels for reporting through faxes and by telephone. However, as Table I shows, increases in the number of reports have been sporadic. On a per capita basis, Canada is considerably behind Australia, where 12000 reports were filed in 20022003 for a country of just over 20 million people.

Right now, only $19 \%$ of Canadian physicians are even aware of the 5 regional reporting centres. Although $92 \%$ of pharmacists know how to file an adverse reaction report, that number drops to $63 \%$ for doctors and $44 \%$ for nurses, and even fewer members of each profession are familiar with where to find the adverse reaction reporting form. ${ }^{11}$

Everyone involved can do a better job of reporting adverse reactions. The importance of reporting needs to be emphasized: this goal should be incorporated into residency programs and highlighted by provincial and national medical associations. The 2005 federal budget committed \$170 million over 5 years to enhance the safety and effectiveness of drugs and other therapeutic products. ${ }^{14}$ Some of that money should be spent on increasing staffing and awareness of the regional centres and ensuring that all those who submit reports are given timely and useful feedback about the reports they have made. Organizations that are advocating consumer reporting need to be encouraged and financially supported. ${ }^{15}$
Joel Lexchin is associate professor, School of Health Policy and Management, York University; emergency physician, University Health Network; and associate professor, Department of Family and Community Medicine, University of Toronto, Toronto, Ont.

Competing interests: None declared.

\section{REFERENCES}

I. Fontanarosa PB, Rennie D, DeAngelis CD. Postmarketing surveillance - lack of vigilance, lack of trust. JAMA 2004;292:2647-50.

2. Juurlink DN, Mamdani MM, Lee DS, et al. Rates of hyperkalemia after publication of the randomized aldactone evaluation study. N Engl J Med 2004;35I:543-5I.

3. Rossi AC, Knapp DE, Anello C, et al. Discovery of adverse drug reactions: a comparison of selected phase IV studies with spontaneous reporting methods. JAMA I983;249:2226-8.

4. Lexchin J. Drug withdrawals from the Canadian market for safety reasons, $1_{9} 63-$ 2004. CMAJ 2005;172(6):765-7.

5. Kernan WN, Viscoli CM, Brass LM, et al. Phenylpropanolamine and the risk of hemorrhagic stroke. N Engl J Med 2000;343:1826-32.

6. Medawar C, Herxheimer A. Risk of suicidality and dependence with paroxetine: comparing yellow card reports of suspected adverse drug reactions with reports from users. Int J Risk Saf Med 2003;16:3-17.

7. Fletcher A. Spontaneous adverse drug reaction reporting vs event monitoring: a comparison. JR Soc Med I99I;84:34I-4.

8. Moride Y, Haramburu F, Requejo A, et al. Under-reporting of adverse drug reactions in general practice. BrJ Clin Pharmacol I997;43:177-8I.

9. Moore T, Psaty B, Furberg C. Time to act on drug safety. JAMA I998;279:157I-3.

Io. Jorup-Rönström C, Britton S. Efficacy of reporting systems of adverse reactions to drugs and care. Scand J Soc Med I983;Ir:87-9.

II. Decima Research Inc. Public opinion survey on key issues pertaining to post-market surveillance of marketed health products in Canada: final report. Ottawa: Health Canada; 2003 December. Report no.: POR 298-02.

I2. Feely J, Moriarty S, O'Connor P. Stimulating reporting of adverse drug reactions by using a fee. BMJ I990;300:22-3.

I3. Goldman SA. Communication of medical product risk: how effective is effective enough? Drug Saf 2004;27:519-34.

14. The budget plan 2005. Ottawa: Department of Finance, Canada; 2005. Report no.: $\mathrm{FI}-23 / 2005-3 \mathrm{E}$.

I5. Priest A. National consumer drug safety network launched. $C M A J$ 2005;172(9):II68.

Correspondence to: Dr. Joel Lexchin, I2I Walmer Rd., Toronto ON M5R2X8; jlexchin@yorku.ca 